\title{
A giant parathyroid cyst manifesting with a neck mass
}

\section{and hypercalcemic crisis}

F. Adamidou ${ }^{1}$, Chr. G. Manani ${ }^{1}$, Ap. Kambaroudis², M. Kita ${ }^{1}$

1. Department of Endocrinology, Hippokrateion General Hospital of Thessaloniki

2. 5th Surgical Department, Hippokrateion General Hospital of Thessaloniki.

\section{Introduction:}

Functional parathyroid cysts represent an uncommon cause of primary hyperparathyroidism (PHPT) and an even rarer cause of a cervical mass.

\section{Case report}

A 57-year-old woman was referred to our department following emergency treatment of hypercalcemic crisis (serum calcium $16.4 \mathrm{mg} / \mathrm{dl}$ ) with intravenous hydration and zoledronic acid. She was found to have multiple vertebral fractures by plain radiographs one month previously. Despite being diagnosed and treated with cinacalcet for PHPT for a year prior to these events and a neck mass was noted, it was considered a cystic thyroid nodule. At presentation she had generalized weakness and leftsided neck discomfort with pressure symptoms. Her corrected serum calcium was $13.1 \mathrm{mg} / \mathrm{dl}$, phosphate 0.9 $\mathrm{mg} / \mathrm{dl}$, PTH $330 \mathrm{pg} / \mathrm{ml}$, alkaline phosphatase 260 (ULN 220 U/L) and kidney function was normal. Past history was notable for partial thyroidectomy in the 70s.

\section{Clinical}

On examination she was ill-looking and a firm, fixed cervical mass was palpable from the sternal notch to the jaw angle. On ultrasound, the mass was cystic with various septa and measured $9 \times 4 \times 4 \mathrm{~cm}$. Needle aspiration of the cyst evacuated $45 \mathrm{ml}$ of hemorrhagic fluid, with PTH washout levels measuring $570 \mathrm{pg} / \mathrm{ml}$. Within the next two weeks, a hematoma formed that resolved uneventfully, but the cyst recurred almost to its original dimensions, again causing local pressure. At surgery, the cyst measured $6.4 \times 4 \times 4 \mathrm{~cm}$ and histology was consistent with hemorrhagic cystic necrosis of parathyroid adenoma surrounded by an intact thick $(0.2-0.5 \mathrm{~cm})$ fibrous capsule without evidence of local invasion. Postoperatively, serum calcium and phosphate were $8.6 \mathrm{mg} / \mathrm{dl}$ and $3.8 \mathrm{mg} / \mathrm{dl}$ respectively. The patient remains normocalcemic on calcium and vitamin D supplementation 9 months after surgery.
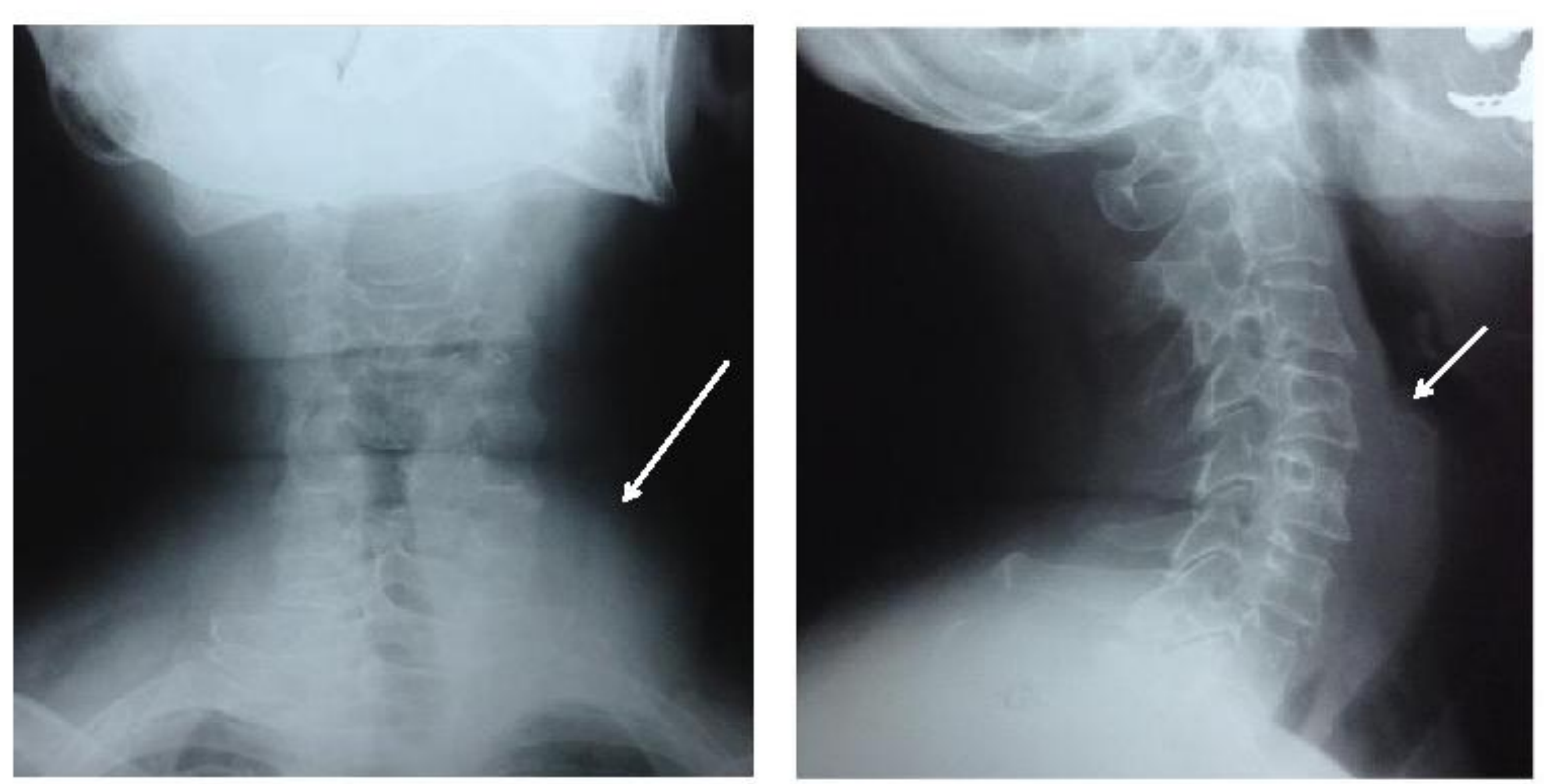

Figure 1, 2: Face and lateral cervical X-Ray

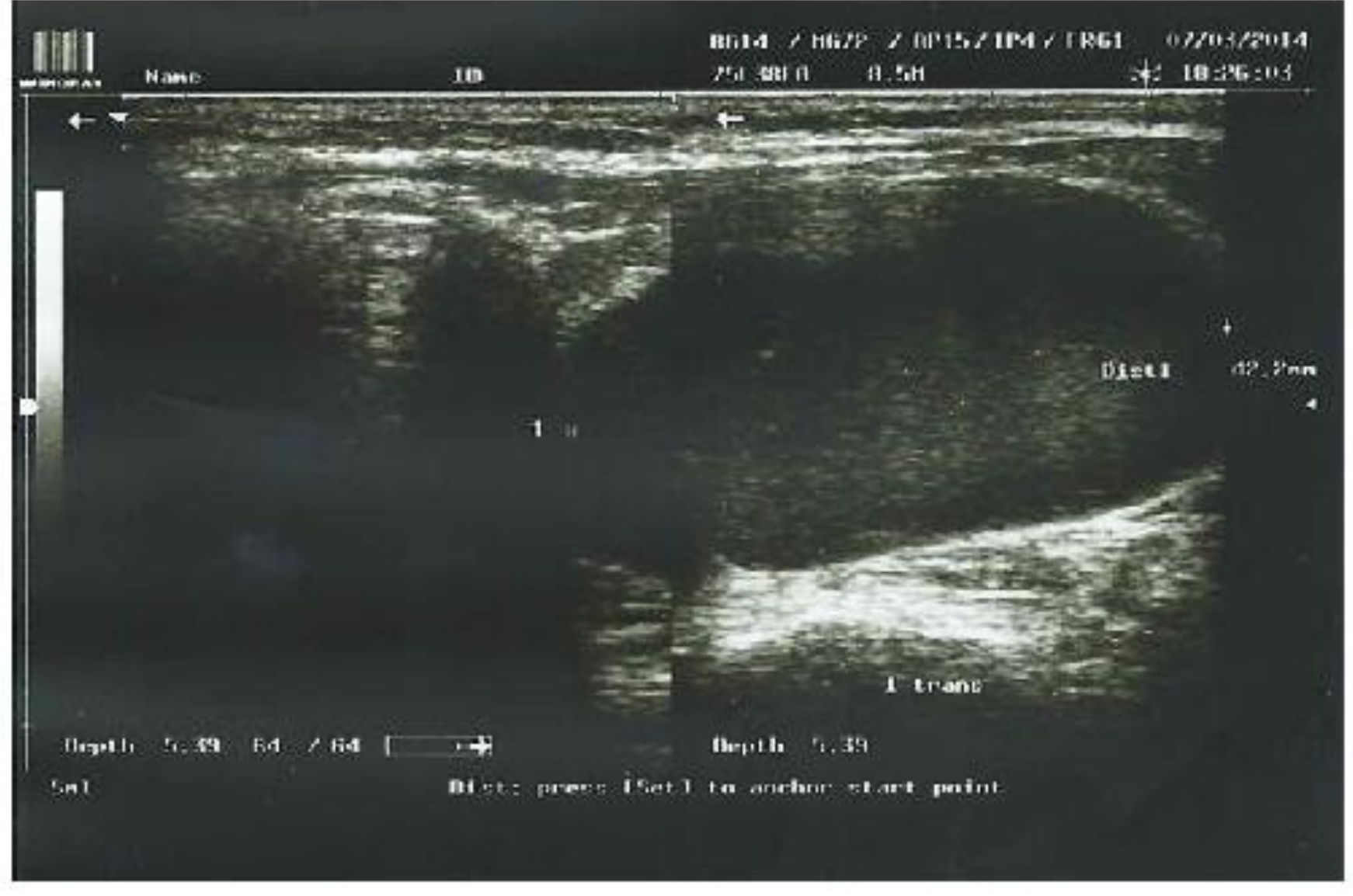

Figure 3: Transverse ultrasound view of the cyst.

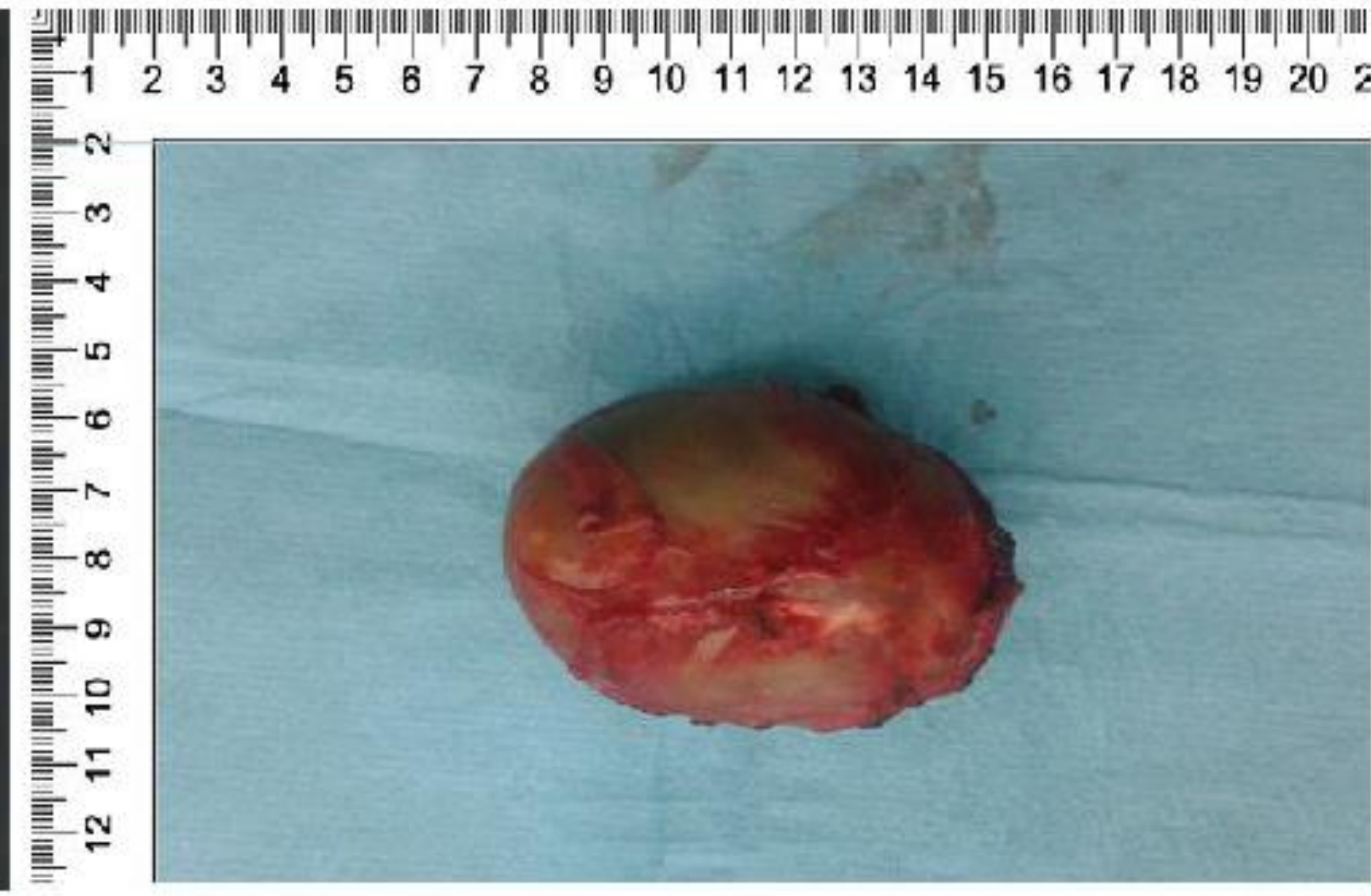

Figure 4: Gross surgical specimen.

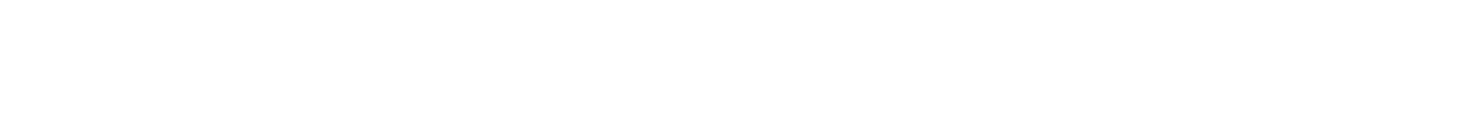

\section{Conclusion}

This case highlights that a large functional parathyroid cyst can elude diagnosis because of its rarity; however, early identification is crucial for proper patient management.

\section{References}

1. G.D.MacKay et al. Giant functioning parathyroid cyst presenting as a retrosternal goitre. ANZ J. Surg 2007; 77: 297-304

2. Asghar et al. A case report: Giant cystic parathyroid adenoma presenting with parathyroid crisis after Vitamin $D$ replacement. $B M C$

Endocrine Disorders 2012, 12:14.

3. P.S.Ihm et al. Parathyroid Cysts: Diagnosis and Management. Laryngoscope 111: Sept. 2001

4. K.L. McCoy et al. Cystic Parathyroid Lesions. Arch. Surg. 2009; 144(1): 52-56 